\title{
Absorção de cátions e ânions pelo capim-coastcross adubado com uréia e nitrato de amônio
}

\author{
Ana Cândida Primavesi ${ }^{(1)}$, Odo Primavesi $i^{(1)}$, Luciano Almeida Corrêa ${ }^{(1)}$, Heitor Cantarella(2) \\ e Aliomar Gabriel da Silva ${ }^{(1)}$
}

\begin{abstract}
(1)Embrapa Pecuária Sudeste, Caixa Postal 339, CEP 13560-970 São Carlos, SP. E-mail: anacan@cppse.embrapa.br, odo@cppse.embrapa.br, luciano@cppse.embrapa.br, aliomar@cppse.embrapa.br (2)Instituto Agronômico de Campinas, Centro de Solos e Recursos Agroambientais, Caixa Postal 28, CEP 13001-970 Campinas, SP. E-mail: cantarella@iac.sp.gov.br
\end{abstract}

Resumo - Os processos fisiológicos das plantas são afetados pelo balanço de cátions e ânions absorvidos. O objetivo deste trabalho foi determinar a absorção de cátions e ânions quando plantas de capim-coastcross receberam doses elevadas de nitrogênio. $\mathrm{O}$ delineamento experimental foi o de blocos casualizados com quatro repetições, num esquema fatorial $2 \times 5$ - duas fontes de $\mathrm{N}$ : uréia e nitrato de amônio, e cinco doses de $\mathrm{N}$ : 0, 25, 50, 100, $200 \mathrm{~kg} \mathrm{ha}^{-1}$ corte $^{-1}$. As doses de $\mathrm{N}$ foram aplicadas após cada corte num total de cinco cortes, durante a época das chuvas. A absorção de cátions e de ânions pelo capim-coastcross aumentou com o acréscimo das doses de $\mathrm{N}$ dos dois fertilizantes, sendo maior com o nitrato de amônio. Com doses crescentes de $\mathrm{N}$, verificouse entre os cátions maior absorção do $\mathrm{K}^{+}$, e do $\mathrm{Cl}^{-}$entre os ânions. Com exceção do $\mathrm{N}$, a absorção do $\mathrm{K}^{+}$foi superior à dos demais nutrientes, com redução no teor relativo de cálcio. Doses altas de $\mathrm{N}$ aplicadas em capimcoastcross, na forma de uréia ou de nitrato de amônio, favorecem a absorção de cátions e de ânions.

Termos para indexação: Cynodon dactylon, absorção de nutrientes, adubos nitrogenados.

\section{Cations and anions uptake by coastcross grass fertilized with urea and ammonium nitrate}

\begin{abstract}
Physiologic processes of plants are affected by uptake of cations and anions. The aim of this work was to determine the uptake of cations and anions when plants of coastcross grass received high doses of nitrogen. The experimental design was a randomized block, in a $2 \times 5$ factorial arrangement - two N sources: urea and ammonium nitrate and five $\mathrm{N}$ rates: $0,25,50,100$, and $200 \mathrm{~kg} \mathrm{ha}^{-1}$ cutting ${ }^{-1}$ - with four replications. Treatments were applied after each of five consecutive cutting in the rainy season. Uptake of cations and anions by coastcross grass increased with increasing of $\mathrm{N}$ rates with both fertilizers, but was higher with ammonium nitrate. Increasing rates of $\mathrm{N}$ caused higher $\mathrm{K}^{+}$uptake in relation to other cations, and in $\mathrm{Cl}^{-}$among the anions. Except for $\mathrm{N}, \mathrm{K}^{+}$uptake was greater than that of other nutrients, with a reduction on the relative content of $\mathrm{Ca}^{2+}$. High doses of $\mathrm{N}$ as urea or ammonium nitrate applied on coastcross grass favor absorption of cations and anions.
\end{abstract}

Index terms: Cynodon dactylon, nutrients absorption, nitrogen fertilizers.

\section{Introdução}

O suprimento de nutrientes em proporções adequadas é essencial para a ótima produção vegetal, mas nem sempre isto é considerado na prática agrícola. A máxima produção vegetal depende da concentração e da proporção entre os nutrientes. O efeito da mudança na dose de suprimento de um ou mais nutrientes na produção vegetal depende do desbalanço gerado em relação aos outros nutrientes. Em muitos casos a quantidade mínima de um nutriente para o crescimento normal não é um valor absoluto, mas depende das quantidades relativas dos outros nutrientes disponíveis (Mengel \& Kirkby, 1987).

Os efeitos fisiológicos dos nutrientes de plantas não podem ser considerados isoladamente. Como ocorrem interações entre os nutrientes, as mudanças são iniciadas no nível subcelular, podendo afetar a fotossíntese, respiração, utilização e translocação de carboidratos. Praticamente todos os fatores que influenciam a absorção de nutrientes pelas culturas também afetam as relações entre eles, com reflexos no desenvolvimento das plantas (Marschner, 1995). 
Íons como $\mathrm{NO}_{3}^{-}, \mathrm{K}^{+}$e $\mathrm{Cl}^{-}$são absorvidos mais rapidamente, enquanto a absorção de $\mathrm{Ca}^{2+}, \mathrm{SO}_{4}^{2-}$ é relativamente lenta. A diferença na taxa de absorção significa que a planta remove cátions e ânions em quantidades desiguais do meio (Mengel \& Kirkby, 1987).

As culturas são capazes de ser altamente seletivas na absorção de cátions. Isso faz com que existam grandes diferenças nas quantidades individuais de cátions absorvidos, em suas concentrações nos tecidos da planta e nas relações entre eles. O balanço de nutrientes pode estar satisfatório para uma dada produção vegetal, mas pode tornar-se inadequado na obtenção de produções maiores, seja por meio da irrigação, ou por doses elevadas de fertilizantes ou pela combinação desses fatores (Mengel \& Kirkby, 1987).

De todos os nutrientes minerais, o Né quantitativamente o mais importante para o crescimento da planta. A forma de fertilizantes nitrogenados $\left(\mathrm{NO}_{3}{ }^{-}, \mathrm{NH}_{4}{ }^{+}\right)$usados na adubação pode influenciar o balanço de cátions-ânions nas plantas (Engels \& Marschner, 1995).

Altas doses de fertilizantes são necessárias para assegurar altas produções de forragem em capins manejados em sistemas intensivos rotacionados, o que aumenta a probabilidade de criar um desbalanço nutricional. Esse assunto é pouco estudado e, com a finalidade de compreendê-lo melhor, é necessário realizar novos trabalhos.

O objetivo deste trabalho foi determinar a absorção de cátions e de ânions quando plantas de capimcoastcross receberam doses elevadas de nitrogênio.

\section{Material e Métodos}

O experimento foi instalado em área com capimcoastcross estabelecida há três anos em Latossolo Vermelho distrófico típico (LVd), textura média, na Embrapa Pecuária Sudeste, São Carlos, SP, (22¹' S e 47054' W; $836 \mathrm{~m}$ de altitude) sob clima tropical. A pastagem vinha sendo explorada intensivamente sob pastejo rotativo com quatro dias de ocupação e 24 dias de descanso, recebendo $300 \mathrm{~kg} \mathrm{ha}^{-1} \mathrm{ano}^{-1}$ de $\mathrm{N}$ na forma de uréia, no período das chuvas.

O experimento foi conduzido de 6/11/1998 a 15/4/1999. O delineamento experimental foi o de blocos casualizados com quatro repetições, num esquema fatorial de $2 \times 5-$ duas fontes de N: uréia e nitrato de amônio e cinco doses de N: 0, 25, 50, 100, $200 \mathrm{~kg} \mathrm{ha}^{-1}$ corte $^{-1}$. As doses de $\mathrm{N}$ foram aplicadas após cada corte, num total de cinco cortes, durante a época das chuvas. A área das parcelas foi de $20 \mathrm{~m}^{2}(4 \times 5 \mathrm{~m})$, com área útil de $6 \mathrm{~m}^{2}$ para avaliação da produção de forragem.

O solo apresentava as seguintes características químicas $(0-20 \mathrm{~cm})$ no início do experimento: $\mathrm{pH}$ em $\mathrm{CaCl}_{2}, 5,6$; MO, $32 \mathrm{~g} \mathrm{dm}^{-3}$; P-resina, $27 \mathrm{mg} \mathrm{dm}^{-3} ; \mathrm{K}^{+}, 5,1 \mathrm{mmol}_{\mathrm{c}} \mathrm{dm}^{-3}$; $\mathrm{Ca}^{2+}, 25 \mathrm{mmol}_{\mathrm{c}} \mathrm{dm}^{-3} ; \mathrm{Mg}^{2+}, 14$ mmol $_{\mathrm{c}} \mathrm{dm}^{-3}$; CTC a pH 7 , $65 \mathrm{mmol}_{\mathrm{c}} \mathrm{dm}^{-3} ; \mathrm{V}, 67 \%$. As análises de solo no início e no término do experimento foram realizadas conforme Raij et al. (2001). A porção de terra destinada para análise do $\mathrm{NO}_{3}{ }^{-}$foi congelada logo após a coleta no campo (Mattos Júnior et al., 1995).

Após o corte de uniformização, todas as parcelas receberam $60 \mathrm{~kg} \mathrm{ha}^{-1}$ de $\mathrm{K}_{2} \mathrm{O}$ (cloreto de potássio). Em seguida ao primeiro corte, todas as parcelas receberam $50 \mathrm{~kg} \mathrm{ha}^{-1}$ de $\mathrm{P}_{2} \mathrm{O}_{5}$ (superfosfato simples) e $30 \mathrm{~kg} \mathrm{ha}^{-1}$ de FTE BR-12 (9,0\% de Zn; $1,8 \%$ de B; $0,8 \%$ de Cu; $3,0 \%$ de $\mathrm{Fe} ; 2,0 \%$ de $\mathrm{Mn} ; 0,1 \%$ de Mo). Após o terceiro corte, todas as parcelas receberam $50 \mathrm{~kg} \mathrm{ha}^{-1}$ de $\mathrm{P}_{2} \mathrm{O}_{5}$ (superfosfato simples). A partir do primeiro corte, a adubação potássica seguiu o critério de repor o $\mathrm{K}^{+}$extraído pela planta, ou seja, teor mínimo de $20 \mathrm{~g} \mathrm{~kg}^{-1}$. Assim, após o primeiro e o segundo cortes, as parcelas adubadas com 0,25 e $50 \mathrm{~kg} \mathrm{ha}^{-1}$ corte $^{-1}$ de $\mathrm{N}$ (uréia e nitrato de amônio) receberam $60 \mathrm{~kg} \mathrm{ha}^{-1}$ de $\mathrm{K}_{2} \mathrm{O}$ (cloreto de potássio) e as parcelas adubadas com 100 e $200 \mathrm{~kg} \mathrm{ha}^{-1}$ corte $^{-1}$ de $\mathrm{N}$ (uréia e nitrato de amônio) receberam $120 \mathrm{~kg} \mathrm{ha}^{-1}$ de $\mathrm{K}_{2} \mathrm{O}$ (cloreto de potássio). Após o terceiro e o quarto cortes, as parcelas adubadas com 0,25 e $50 \mathrm{~kg} \mathrm{ha}^{-1}$ corte $^{-1} \mathrm{de}$ $\mathrm{N}$ (uréia e nitrato de amônio) receberam $100 \mathrm{~kg} \mathrm{ha}^{-1}$ de $\mathrm{K}_{2} \mathrm{O}$ (cloreto de potássio), e as parcelas que foram adubadas com 100 e $200 \mathrm{~kg} \mathrm{ha}^{-1}$ corte $^{-1}$ de $\mathrm{N}$ (uréia e nitrato de amônio) receberam $200 \mathrm{~kg} \mathrm{ha}^{-1} \mathrm{de}_{2} \mathrm{O}$ (cloreto de potássio).

Os cortes foram realizados em intervalos de 24 dias, que é o período de pastejo usado na área, e a $10 \mathrm{~cm}$ da superfície do solo. Após a determinação da massa de matéria fresca foi separada uma amostra de $500 \mathrm{~g}$, secada em estufa de circulação forçada de ar a $60^{\circ} \mathrm{C}$ até massa constante, para determinação da massa de matéria seca, e posterior análise dos nutrientes (Malavolta et al., 1989). Os teores de $\mathrm{NO}_{3}{ }^{-}$no tecido vegetal foram determinados segundo Tedesco et al. (1985).

Os resultados da análise do tecido vegetal foram provenientes da média dos cinco cortes efetuados, e expressos em mmol $_{\mathrm{c}} \mathrm{kg}^{-1}$, considerando o $\mathrm{N}, \mathrm{P} \mathrm{Cl}^{-}$e $\mathrm{K}^{+}$

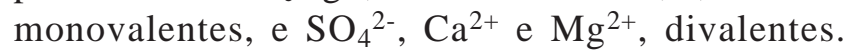


Os valores de $\mathrm{P}$ foram convertidos em $\mathrm{H}_{2} \mathrm{PO}_{4}^{-}$, os de $\mathrm{N}$ em $\mathrm{NO}_{3}{ }^{-}$e os de $\mathrm{S}$ em $\mathrm{SO}_{4}{ }^{2-}$. No balanço dos nutrientes, foram considerados os cátions $\mathrm{Ca}^{2+}, \mathrm{Mg}^{2+} \mathrm{e} \mathrm{K} \mathrm{K}^{+}$, e os ânions $\mathrm{SO}_{4}^{2-}, \mathrm{H}_{2} \mathrm{PO}_{4}^{-}, \mathrm{Cl}^{-}$e $\mathrm{NO}_{3}^{-}$. Não foram considerados os micronutrientes, exceto o $\mathrm{Cl}^{-}$.

$\mathrm{O}$ balanço de cargas internas na planta é feito por meio da síntese de compostos orgânicos, especialmente ânions orgânicos, e excreção de prótons e hidroxilas ou bicarbonatos pelas raízes. Neste estudo não foram considerados os ânions orgânicos e também não foi possível saber a forma como o $\mathrm{N}$ foi absorvido pela planta.

Os valores de concentração e absorção dos nutrientes foram expressos em $\mathrm{mmol}_{\mathrm{c}} \mathrm{kg}^{-1}$ de matéria seca de forragem e $\mathrm{mmol}_{\mathrm{c}} \mathrm{ha}^{-1}$, respectivamente, com a finalidade de facilitar as comparações.

Os dados foram submetidos à análise de variância. O teste F, usado para testar a significância dos componentes linear e quadrático das curvas de regressão, e o teste DMS (diferença mínima significativa) foram usados na comparação entre as fontes de nitrogênio.

\section{Resultados e Discussão}

A aplicação de um nutriente, em geral, promove o crescimento da planta e aumenta o teor deste e, em alguns casos, o teor de outros nutrientes (sinergismo)
(Marschner, 1995). As doses crescentes de N, em especial o nitrato de amônio, propiciaram aumentos nos

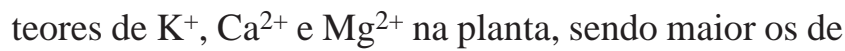
$\mathrm{K}^{+}$; também ocorreu aumento nos teores de $\mathrm{Cl}^{-}, \mathrm{N}$ total e $\mathrm{NO}_{3}{ }^{-}$solúvel no tecido vegetal, e redução nos de $\mathrm{H}_{2} \mathrm{PO}_{4}{ }^{-}$e $\mathrm{SO}_{4}{ }^{2-}$, principalmente com o nitrato de amônio (Tabela 1). Houve maior absorção de cátions do que de ânions, o que talvez tenha sido compensado pela maior absorção de $\mathrm{N}$ total, possivelmente na forma de nitrato.

Com doses altas de $\mathrm{N}$ e curto intervalo de cortes das plantas, houve pequeno acúmulo de $\mathrm{NO}_{3}{ }^{-}$solúvel na forragem (Tabela 1), sendo pouco expressivo, pois o limite de teores tóxicos para os animais está entre $243 \mathrm{e}^{2} 321 \mathrm{mmol}_{\mathrm{c}} \mathrm{kg}^{-1} \mathrm{de} \mathrm{NO}_{3}{ }^{-}$ $\left(0,34\right.$ a $0,45 \%$ de $\mathrm{N}$ na forma de $\left.\mathrm{NO}_{3}^{-}\right)$na forragem fresca (Whitehead, 1995), correspondendo, respectivamente, a 3.400 e $4.500 \mathrm{mg} \mathrm{kg}^{-1}$ de nitrogênio na forma de nitrato. Mesmo nas maiores doses de $\mathrm{N}$, esses teores e os relatados por Cantarella et al. (2002) estão abaixo do limite tóxico, indicando boa metabolização de $\mathrm{N}$ pela planta, confirmada pela grande produção de massa de matéria seca (Corrêa et al., 2001).

A absorção de cátions aumentou com o acréscimo das doses de $\mathrm{N}$ de ambos os fertilizantes, mas o efeito foi maior com o $\mathrm{K}^{+}$, e com o nitrato de amônio (Tabe-

Tabela 1. Efeito de doses e de fontes de N na concentração (média de cinco cortes) e no balanço de nutrientes na parte aérea de capim-coastcross ${ }^{(1)}$.

\begin{tabular}{|c|c|c|c|c|c|c|c|c|c|c|c|c|}
\hline $\mathrm{N}$ & $\mathrm{K}^{+}$ & $\mathrm{Ca}^{2+}$ & $\mathrm{Mg}^{2+}$ & $\mathrm{H}_{2} \mathrm{PO}_{4}^{-}$ & $\mathrm{SO}_{4}^{2-}$ & $\mathrm{Cl}^{-}$ & $\begin{array}{l}\mathrm{NO}_{3}^{-} \\
\text {solúvel }\end{array}$ & $\begin{array}{l}\mathrm{N} \\
\text { total }\end{array}$ & $\begin{array}{l}\text { Total de } \\
\text { cátions }\end{array}$ & $\begin{array}{l}\text { Total de } \\
\text { ânions }\end{array}$ & $\begin{array}{l}\text { Diferença entre } \\
\text { cátions e ânions }\end{array}$ & $\begin{array}{l}\text { Cátions/ } \\
\text { ânions }\end{array}$ \\
\hline$\left(\mathrm{kg} \mathrm{ha}^{-1}\right)$ & & & & & & $(\mathrm{mmc}$ & $\left(g^{-1}\right)$ & & & & & \\
\hline & \multicolumn{12}{|c|}{ Uréia } \\
\hline 0 & 430 & 174 & 153 & 96 & 196 & 143 & 1 & 1.175 & 758 & 436 & 322 & 1,74 \\
\hline 25 & 472 & 179 & 162 & 95 & 197 & 187 & 1 & 1.199 & 813 & 480 & 333 & 1,69 \\
\hline 50 & 521 & 174 & 168 & 96 & 192 & 224 & 1 & 1.332 & 863 & 514 & 349 & 1,68 \\
\hline 100 & 621 & 185 & 192 & 94 & 213 & 294 & 5 & 1.547 & 997 & 606 & 391 & 1,64 \\
\hline 200 & 662 & 192 & 214 & 89 & 191 & 281 & 35 & 1.951 & 1.067 & 595 & 472 & 1,79 \\
\hline Média & 541 & 181 & 178 & 94 & 198 & 226 & 9 & 1.441 & 900 & 526 & 353 & 1,71 \\
\hline Teste $\mathrm{F}$ & $\mathrm{L}^{* *}$ & $\mathrm{~L}^{*}$ & $\mathrm{Q}^{*}$ & $\mathrm{~L}^{*}$ & $\mathrm{~ns}$ & $\mathrm{Q}^{* *}$ & $\mathrm{Q}^{* *}$ & $\mathrm{Q}^{* *}$ & $\mathrm{~L}^{*}$ & $\mathrm{~L}^{*}$ & $\mathrm{Q}^{* *}$ & \\
\hline & \multicolumn{12}{|c|}{ Nitrato de amônio } \\
\hline 0 & 548 & 188 & 183 & 115 & 253 & 151 & 0 & 1.220 & 919 & 558 & 360 & 1,65 \\
\hline 25 & 506 & 180 & 165 & 99 & 201 & 197 & 1 & 1.277 & 851 & 498 & 352 & 1,71 \\
\hline 50 & 564 & 186 & 186 & 95 & 212 & 247 & 2 & 1.413 & 936 & 556 & 380 & 1,68 \\
\hline 100 & 696 & 187 & 209 & 89 & 197 & 301 & 17 & 1.827 & 1.092 & 605 & 487 & 1,80 \\
\hline 200 & 787 & 194 & 227 & 87 & 185 & 264 & 51 & 2.191 & 1.208 & 588 & 620 & 2,05 \\
\hline Média & 620 & 187 & 194 & 97 & 210 & 232 & 14 & 1.586 & 1.001 & 561 & 440 & 1,78 \\
\hline Teste F & $\mathrm{Q}^{* *}$ & ns & $\mathrm{Q}^{* *}$ & $\mathrm{Q}^{* *}$ & $\mathrm{~L}^{*}$ & $\mathrm{Q}^{* *}$ & $\mathrm{Q}^{* *}$ & $\mathrm{Q}^{* *}$ & $\mathrm{Q}^{* *}$ & $\mathrm{~L}^{*}$ & $\mathrm{Q}^{* *}$ & \\
\hline DMS & $47^{*}$ & ns & $16^{*}$ & ns & ns & ns & $4^{*}$ & $50^{* *}$ & $65^{*}$ & $32^{*}$ & $46^{*}$ & \\
\hline
\end{tabular}

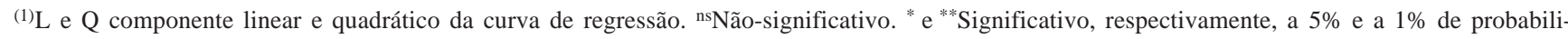
dade, pelo teste F (componente linear e quadrático da curva de regressão) e DMS (diferença mínima significativa entre as médias das fontes de nitrogênio). 
la 2). Raij et al. (1988) também relatam efeito positivo do $\mathrm{N}$ sobre a absorção de $\mathrm{K}^{+}$, em sorgo.

A porcentagem da concentração dos cátions em relação à sua concentração total, na média das cinco doses de $\mathrm{N}$, foi de $60 \%$ com K $\mathrm{K}^{+}, 20 \%$ com $\mathrm{Ca}^{2+}$ e $20 \%$ com $\mathrm{Mg}^{2+}$ quando se usou a uréia, e $61 \%, 19 \%$ e $20 \%$, respectivamente, com o nitrato de amônio (Tabela 3). Com o acréscimo das doses de N, ocorreu aumento linear da participação do $\mathrm{K}^{+}$e decréscimo linear da do $\mathrm{Ca}^{2+}$, indicando também maior absorção de $\mathrm{K}^{+}$.

Quando o N é absorvido como $\mathrm{NO}_{3}{ }^{-}$ocorre competição com os outros ânions e aumento na absorção de cátions para manter o equilíbrio iônico nos tecidos das plantas (Engels \& Marschner, 1995). A absorção dos cátions pelas plantas foi maior que a dos ânions, não considerando a do $\mathrm{N}$, com ambos fertilizantes, e maior para o nitrato de amônio que apresenta $50 \%$ do seu $\mathrm{N}$ na forma de $\mathrm{NH}_{4}{ }^{+}$(Tabela 2). Provavelmente ocorreu maior absorção pelas plantas do $\mathrm{N}$ na forma de $\mathrm{NO}_{3}{ }^{-}$ com ambos os fertilizantes.

Em virtude do curto intervalo de cortes, pode ter ocorrido rápida nitrificação quando se aplicou uréia, uma vez que o conteúdo de $\mathrm{N}$ desse fertilizante se encontra na forma amídica. Como o pH inicial do solo era suficientemente alto para provocar rápida nitrificação do $\mathrm{NH}_{4}{ }^{+}$, tanto do nitrato de amônio quanto da hidrólise da uréia, pode-se inferir que as plantas absorveram mais $\mathrm{NO}_{3}{ }^{-}$ do que $\mathrm{NH}_{4}{ }^{+}$. Mello (1987), citando diversos autores, relata que a nitrificação está relacionada ao $\mathrm{pH}$ do solo, com faixa ótima em torno de 7,0, mas também pode ocorrer em solo com $\mathrm{pH}$ próximo de 4,0. Embora o pH do solo, após o término deste experimento, na camada de $0-10 \mathrm{~cm}$, tenha apresentado tendência de redução com a dose de $200 \mathrm{~kg} \mathrm{ha}^{-1}$ corte $^{-1} \mathrm{de} \mathrm{N}$, sendo esta mais acentuada com o nitrato de amônio, isto não impediu a nitrificação, confirmada pelos íons $\mathrm{NO}_{3}{ }^{-}$no solo quando foi usado o nitrato de amônio (Tabela 4). A presença desses íons também indica maior absorção de $\mathrm{NO}_{3}{ }^{-}$pelas plantas adubadas com a maior dose de $\mathrm{N}$, em especial com nitrato de amônio.

Cox \& Reisenauer (1973) verificaram em trigo que o aumento da taxa de absorção de $\mathrm{NO}_{3}{ }^{-}$elevou a taxa de absorção de $\mathrm{P}, \mathrm{K}^{+}, \mathrm{Ca}^{2+} \mathrm{e} \mathrm{Mg}^{2+}$, quando eram fornecidos $\mathrm{NO}_{3}{ }^{-}$e $\mathrm{NO}_{3}{ }^{-}+\mathrm{NH}_{4}{ }^{+}$, mas quando foi fornecido somente $\mathrm{NH}_{4}{ }^{+}$, aumentos na taxa de absorção de $\mathrm{NH}_{4}{ }^{+}$ reduziram a absorção de $\mathrm{Ca}^{2+}$ e $\mathrm{Mg}^{2+}$. Também foi verificado aumento na taxa de absorção de $\mathrm{P}, \mathrm{K}^{+}, \mathrm{Ca}^{2+}$ e $\mathrm{Mg}^{2+}$, evidenciando que as plantas absorveram mais $\mathrm{NO}_{3}{ }^{-}$que $\mathrm{NH}_{4}{ }^{+}$(Tabela 2).

Raij \& Diest (1979) verificaram em trigo-sarraceno maior absorção de cátions, causando acidificação do solo. Além disso, o trigo absorveu mais ânions, aumentando o pH do solo, indicando excreção de $\mathrm{HCO}_{3}{ }^{-}$na rizosfera (Föhse et al., 1991). Raij et al. (1988) verifi-

Tabela 2. Efeito de doses e de fontes de N na absorção de nutrientes e na produção de matéria seca (MS) da forragem de capimcoastcross. Média de cinco cortes ${ }^{(1)}$.

\begin{tabular}{|c|c|c|c|c|c|c|c|c|c|c|c|c|}
\hline $\begin{array}{c}\mathrm{N} \\
\left(\mathrm{kg} \mathrm{ha}^{-1}\right)\end{array}$ & $\mathrm{K}^{+}$ & $\mathrm{Ca}^{2+}$ & $\mathrm{Mg}^{2+}$ & $\mathrm{H}_{2} \mathrm{PO}_{4}^{-}$ & $\mathrm{SO}_{4}{ }^{2-}$ & $\mathrm{Cl}^{-}$ & $\mathrm{NO}_{3}^{-}$ & $\mathrm{N}$ total & $\begin{array}{l}\text { Total de } \\
\text { cátions }\end{array}$ & $\begin{array}{l}\text { Total de } \\
\text { ânions }\end{array}$ & $\begin{array}{l}\text { Diferença entre } \\
\text { cátions e ânions }\end{array}$ & $\begin{array}{c}\text { MS } \\
\left(\mathrm{kg} \mathrm{ha}^{-1}\right)\end{array}$ \\
\hline \multicolumn{13}{|c|}{ Uréia } \\
\hline 0 & 328 & 145 & 131 & 82 & 166 & 118 & 1 & 976 & 604 & 366 & 238 & 799 \\
\hline 25 & 681 & 268 & 245 & 143 & 298 & 281 & 1 & 1.818 & 1.194 & 724 & 470 & 1.431 \\
\hline 50 & 1.091 & 383 & 376 & 213 & 420 & 525 & 3 & 2.916 & 1.851 & 1.161 & 690 & 2.176 \\
\hline 100 & 1.749 & 544 & 571 & 268 & 618 & 896 & 20 & 4.553 & 2.864 & 1.801 & 1.062 & 2.886 \\
\hline 200 & 2.239 & 666 & 761 & 299 & 649 & 954 & 159 & 6.787 & 3.666 & 2.061 & 1.605 & 3.448 \\
\hline Média & 1.218 & 401 & 417 & 201 & 430 & 555 & 37 & 3.410 & 2.036 & 1.223 & 813 & 2.148 \\
\hline Teste F & $\mathrm{L}^{* *}$ & $\mathrm{~L}^{* *}$ & $\mathrm{Q}^{*}$ & $\mathrm{~L}^{* *}$ & $\mathrm{~L}^{* *}$ & $\mathrm{~L}^{* *}$ & $\mathrm{Q}^{* *}$ & $\mathrm{Q}^{* *}$ & $\mathrm{~L}^{* *}$ & $\mathrm{~L}^{* *}$ & $Q^{*}$ & $\mathrm{~L}^{* *}$ \\
\hline \multicolumn{13}{|c|}{ Nitrato de amônio } \\
\hline 0 & 351 & 118 & 116 & 72 & 160 & 124 & 0 & 1.014 & 585 & 358 & 228 & 821 \\
\hline 25 & 904 & 330 & 303 & 182 & 376 & 369 & 2 & 2.295 & 1.537 & 929 & 608 & 1.782 \\
\hline 50 & 1.484 & 515 & 518 & 258 & 585 & 688 & 4 & 3.865 & 2.518 & 1.535 & 983 & 2.677 \\
\hline 100 & 2.393 & 664 & 748 & 309 & 705 & 1.069 & 67 & 6.375 & 3.806 & 2.149 & 1.657 & 3.501 \\
\hline 200 & 2.922 & 732 & 854 & 330 & 694 & 1.001 & 192 & 8.197 & 4.508 & 2.217 & 2.291 & 3.777 \\
\hline Média & 1.607 & 478 & 512 & 232 & 506 & 650 & 53 & 4.349 & 2.596 & 1.387 & 1.200 & 2.512 \\
\hline Teste F & $\mathrm{L}^{* *}$ & $\mathrm{Q}^{* *}$ & $\mathrm{~L}^{* *}$ & $\mathrm{Q}^{* *}$ & $\mathrm{Q}^{* *}$ & $\mathrm{Q}^{* *}$ & $\mathrm{Q}^{* *}$ & $\mathrm{Q}^{* *}$ & $\mathrm{~L}^{* *}$ & $\mathrm{Q}^{* *}$ & $\mathrm{Q}^{* *}$ & $\mathrm{Q}^{* *}$ \\
\hline DMS & $106^{* *}$ & $32^{* *}$ & $36^{* *}$ & $14^{* *}$ & $53^{*}$ & $45^{* *}$ & $\mathrm{~ns}$ & $234^{* *}$ & $260^{* *}$ & $93^{* *}$ & $208^{*}$ & $114^{* *}$ \\
\hline
\end{tabular}

${ }^{(1)} \mathrm{L}$ e Q componente linear e quadrático da curva de regressão. ${ }^{\text {ns Não-significativo. }}{ }^{*} \mathrm{e}{ }^{* *}$ Significativo, respectivamente, a $5 \%$ e a $1 \%$ de probabilidade, pelo teste F (componente linear e quadrático da curva de regressão) e DMS (diferença mínima significativa entre as médias das fontes de nitrogênio). 
caram em sorgo absorção alcalina (maior absorção de ânions) com nitrato de cálcio e de magnésio; absorção acídica (maior absorção de cátions) com o sulfato de amônio; e pequena absorção de cátions, porém maior que a de ânions, com nitrato de amônio. $\mathrm{O}$ pH da camada 0-10 cm do solo, no final do experimento, sofreu redução no tratamento que recebeu $200 \mathrm{~kg} \mathrm{ha}^{-1}$ corte $^{-1}$ de $\mathrm{N}$ com os dois adubos, maior com nitrato de amônio

Tabela 3. Efeito de doses e de fontes de $\mathrm{N}$ na porcentagem da concentração dos nutrientes em relação à sua concentração total. Média de cinco cortes $^{(1)}$.

\begin{tabular}{|c|c|c|c|c|c|c|c|}
\hline \multirow{3}{*}{$\begin{array}{c}\mathrm{N} \\
\left(\mathrm{kg} \mathrm{ha}^{-1}\right)\end{array}$} & $\mathrm{K}^{+}$ & $\mathrm{Ca}^{2+}$ & $\mathrm{Mg}^{2+}$ & $\mathrm{H}_{2} \mathrm{PO}_{4}$ & $\mathrm{SO}_{4}^{2}$ & $\mathrm{Cl}^{-}$ & $\mathrm{NO}_{3}$ \\
\hline & \multicolumn{3}{|c|}{-- (\% dos cátions)-- } & \multicolumn{4}{|c|}{---- (\% dos ânions) ---- } \\
\hline & \multicolumn{7}{|c|}{ Uréia } \\
\hline 0 & 57 & 23 & 20 & 22 & 45 & 33 & 0,1 \\
\hline 25 & 58 & 22 & 20 & 20 & 41 & 39 & 0,2 \\
\hline 50 & 60 & 20 & 20 & 19 & 37 & 44 & 0,2 \\
\hline 100 & 62 & 19 & 19 & 16 & 35 & 48 & 0,9 \\
\hline 200 & 62 & 18 & 20 & 15 & 32 & 47 & 5,8 \\
\hline Média & 60 & 20 & 20 & 18 & 38 & 42 & 1,4 \\
\hline \multirow[t]{2}{*}{ Teste F } & $\mathrm{L}^{* *}$ & $L^{* *}$ & ns & $\mathrm{L}^{* *}$ & $\mathrm{~L}^{* *}$ & $\mathrm{Q}^{* *}$ & $\mathrm{Q}^{* *}$ \\
\hline & \multicolumn{7}{|c|}{ Nitrato de amônio } \\
\hline 0 & 60 & 20 & 20 & 21 & 45 & 34 & 0,0 \\
\hline 25 & 58 & 22 & 20 & 20 & 40 & 39 & 0,3 \\
\hline 50 & 60 & 20 & 20 & 17 & 38 & 44 & 0,3 \\
\hline 100 & 64 & 17 & 19 & 15 & 32 & 50 & 2,7 \\
\hline 200 & 65 & 16 & 19 & 15 & 31 & 45 & 8,7 \\
\hline Média & 61 & 19 & 20 & 17 & 38 & 42 & 2,4 \\
\hline Teste F & $\mathrm{L}^{* *}$ & $\mathrm{Q}^{*}$ & ns & $\mathrm{L}^{* *}$ & $\mathrm{~L}^{* *}$ & $\mathrm{Q}^{* *}$ & $\mathrm{Q}^{* *}$ \\
\hline DMS & $\mathrm{ns}$ & $1^{*}$ & ns & $\mathrm{ns}$ & ns & ns & $1^{*}$ \\
\hline
\end{tabular}

${ }^{(1)} \mathrm{L}$ e Q componente linear e quadrático da curva de regressão. ${ }^{\text {ns Não- }}$ significativo. ${ }^{*} \mathrm{e}^{* *}$ Significativo, respectivamente, a $5 \%$ e a $1 \%$ de probabilidade, pelo teste $\mathrm{F}$ (componente linear e quadrático da curva de regressão) e DMS (diferença mínima significativa entre as médias das fontes de nitrogênio).
(Tabela 4), o contrário do esperado quando ocorre absorção maior de ânions e o N é absorvido preferencialmente como $\mathrm{NO}_{3}{ }^{-}$. Jarvis \& Robson (1983) verificaram pequeno decréscimo na acidez do solo quando as plantas de trevo absorviam $\mathrm{NO}_{3}{ }^{-}$e atribuíram o fato à possibilidade dos íons básicos, excretados pelas plantas, terem sido removidos por lixiviação.

O nitrato de amônio geralmente acidifica menos que a uréia (Malavolta, 1981), porque fornece potencialmente menos $\mathrm{NH}_{4}{ }^{+}$, cuja nitrificação reduz o pH do solo. Portanto, esperar-se-ia redução menor no pH do solo com nitrato de amônio, pois a metade do $\mathrm{N}$ já está na forma de $\mathrm{NO}_{3}{ }^{-}$, o contrário do observado neste trabalho, e corroborado por Mello (1987) e Cantarella et al. (2003). Porém, a diferença na absorção de cátions e ânions foi maior com nitrato de amônio. Kirkby \& Knight (1977) relatam que plantas supridas com $\mathrm{N}$ na forma de nitrato aumentam a síntese de ânions orgânicos, com aumento na absorção dos cátions inorgânicos $\mathrm{K}^{+}, \mathrm{Ca}^{2+} \mathrm{e} \mathrm{Mg}^{2+}$. Portanto, o valor baixo do $\mathrm{pH}$ final do solo pode ter sido induzido pelas plantas para manter o equilíbrio iônico em seus tecidos, pela maior absorção de $\mathrm{Ca}^{2+}, \mathrm{Mg}^{2+} \mathrm{e}$ $\mathrm{K}^{+}$, provocando a excreção de íons $\mathrm{H}^{+}$(Engels \& Marschner, 1995). A absorção de $\mathrm{NO}_{3}{ }^{-}$também pode ocorrer com troca de $\mathrm{OH}^{-}$sem absorção de cátions (Kirkby \& Amstrong, 1980). Esta troca $\mathrm{NO}_{3}{ }^{-} / \mathrm{OH}^{-}$parece predominar nos capins, cuja absorção de ânions é quase duas vezes a de cátions (Mengel \& Kirkby, 1987). Provavelmente no capim-coastcross a absorção de $\mathrm{NO}_{3}{ }^{-}$ induziu a absorção dos cátions (Tabela 2).

As plantas adubadas com uréia apresentaram menor absorção de $\mathrm{N}$, que pode ser devida às perdas por

Tabela 4. Resultados da análise de solo após o término do experimento.

\begin{tabular}{|c|c|c|c|c|c|c|c|c|c|c|}
\hline \multirow{2}{*}{$\begin{array}{l}\text { Profundidade } \\
(\mathrm{cm})\end{array}$} & \multicolumn{5}{|c|}{ Uréia } & \multicolumn{5}{|c|}{ Nitrato de amônio } \\
\hline & $\begin{array}{c}\mathrm{pH} \\
\left(\mathrm{CaCl}_{2}\right)\end{array}$ & $\begin{array}{c}\mathrm{V} \\
(\%)\end{array}$ & $\mathrm{N}_{-} \mathrm{NH}_{4}^{+}$ & $\begin{array}{r}\mathrm{N}-\mathrm{NO}_{3}^{-} \\
-\left(\mathrm{mg} \mathrm{dm}^{-3}\right.\end{array}$ & $\mathrm{S}^{-\mathrm{SO}_{4}{ }^{2-}}$ & $\begin{array}{c}\mathrm{pH} \\
\left(\mathrm{CaCl}_{2}\right)\end{array}$ & $\begin{array}{l}\mathrm{V} \\
(\%)\end{array}$ & $\mathrm{N}-\mathrm{NH}_{4}^{+}$ & $\begin{array}{l}\mathrm{N}-\mathrm{NO}_{3}^{-} \\
\left.\mathrm{ng} \mathrm{dm}^{-3}\right)\end{array}$ & $\mathrm{S}-\mathrm{SO}_{4}{ }^{2-}$ \\
\hline \multicolumn{11}{|c|}{$0 \mathrm{~kg} \mathrm{ha}^{-1}$ de $\mathrm{N}$} \\
\hline $0-10$ & 6,0 & 74 & 12 & 2 & 7 & 6,0 & 74 & 12,0 & 2,0 & 7 \\
\hline $10-20$ & 5,5 & 60 & 9 & 1 & 16 & 5,5 & 60 & 9,0 & 1,0 & 16 \\
\hline $20-40$ & 4,8 & 33 & 7 & 2 & 39 & 4,8 & 33 & 7,0 & 2,0 & 39 \\
\hline $40-60$ & 4,6 & 25 & 8 & 1 & 27 & 4,6 & 25 & 8,0 & 1,0 & 27 \\
\hline \multicolumn{11}{|c|}{$50 \mathrm{~kg} \mathrm{ha}^{-1} \mathrm{de} \mathrm{N}$} \\
\hline $0-10$ & 5,9 & 73 & 10 & 2 & 7 & 5,9 & 75 & 10,5 & 0,4 & 5 \\
\hline $10-20$ & 5,4 & 56 & 10 & 3 & 11 & 5,6 & 62 & 9,0 & 0,8 & 10 \\
\hline $20-40$ & 4,9 & 36 & 7 & 1 & 27 & 4,8 & 35 & 7,5 & 0,3 & 32 \\
\hline $40-60$ & 4,6 & 22 & 5 & 1 & 22 & 4,6 & 25 & 5,7 & 0,7 & 46 \\
\hline \multicolumn{11}{|c|}{$200 \mathrm{~kg} \mathrm{ha}^{-1}$ de N } \\
\hline $0-10$ & 5,7 & 70 & 9 & 5 & 6 & 5,1 & 55 & 6,7 & 14,1 & 8 \\
\hline $10-20$ & 5,6 & 65 & 9 & 6 & 14 & 5,1 & 58 & 7,6 & 21,9 & 15 \\
\hline $20-40$ & 5,1 & 44 & 7 & 3 & 32 & 4,8 & 37 & 7,3 & 12,1 & 31 \\
\hline $40-60$ & 4,6 & 26 & 7 & 3 & 31 & 4,5 & 25 & 5,2 & 17,0 & 25 \\
\hline
\end{tabular}


volatilização de $\mathrm{NH}_{3}$ da uréia (Cantarella et al., 2001) (Tabela 2). Com nitrato de amônio provavelmente as plantas absorveram mais $\mathrm{N}$ na forma de nitrato, principalmente nas doses mais elevadas de $\mathrm{N}$, pois com a uréia, todo o $\mathrm{N}$ é inicialmente convertido a $\mathrm{NH}_{4}{ }^{+}$.

A acidificação do solo também está associada com a depleção de cátions básicos por causa da lixiviação de $\mathrm{NO}_{3}{ }^{-}$(Bouman et al., 1995). Grandes perdas de $\mathrm{N}$ pela volatilização de $\mathrm{NH}_{3}$ da uréia podem explicar a diferença entre fontes na acidificação do solo, porque essas perdas reduzem o acúmulo de $\mathrm{N}$ inorgânico no solo, e menos nitrato é lixiviado com uréia (Cantarella et al., 2003). Provavelmente, esse decréscimo do $\mathrm{pH}$ também seja verificado porque, em doses altas de $\mathrm{N}$ com o nitrato de amônio, os teores de $\mathrm{N}$ na forma de $\mathrm{NO}_{3}{ }^{-}$no solo eram mais elevados que em doses baixas de $\mathrm{N}$ (Primavesi et al., 2001).

A absorção de ânions aumentou com o acréscimo das doses de N, sendo maior com o nitrato de amônio (Tabela 2), mesmo para os elementos cujo teor na de matéria seca diminuiu por causa do grande aumento da produção de forragem (Tabela 1). A absorção do $\mathrm{Cl}^{-}$ foi superior à dos demais ânions, exceto provavelmente à do $\mathrm{NO}_{3}{ }^{-}$. Com nitrato de amônio, a absorção do $\mathrm{Cl}^{-}$ aumentou até a dose de $100 \mathrm{~kg} \mathrm{ha}^{-1}$ corte $^{-1} \mathrm{de} \mathrm{N}$, e decresceu na dose de $200 \mathrm{~kg} \mathrm{ha}^{-1}$ corte $^{-1}$ de $\mathrm{N}$, embora maior quantidade de $\mathrm{Cl}^{-}$tenha sido fornecida às plantas nas parcelas que receberam 100 e $200 \mathrm{~kg} \mathrm{ha}^{-1}$ corte $^{-1}$ de $\mathrm{N}$, indicando provável competição aniônica com $\mathrm{NO}_{3}{ }^{-}$, que chegou a acumular em forma solúvel.

$\mathrm{O}$ aumento das doses de $\mathrm{N}$ provocou decréscimo linear da porcentagem da concentração dos ânions em relação à sua concentração total, com $\mathrm{H}_{2} \mathrm{PO}_{4}{ }^{-} \mathrm{e} \mathrm{SO}_{4}{ }^{2-}$, e aumento com $\mathrm{Cl}^{-}$até a dose $100 \mathrm{~kg} \mathrm{ha}^{-1}$ corte $^{-1} \mathrm{de} \mathrm{N}$, indicando também maior absorção de $\mathrm{Cl}^{-}$em relação aos outros nutrientes (Tabela 3). A absorção do $\mathrm{Cl}^{-}$, muitas vezes subestimada, foi maior que a do $\mathrm{SO}_{4}{ }^{2-}$ e a $\mathrm{doH}_{2} \mathrm{PO}_{4}^{-}$, independentemente da fonte de nitrogênio. Isto pode ter sido verificado em virtude de os íons $\mathrm{NO}_{3}{ }^{-}, \mathrm{K}^{+} \mathrm{e}$ $\mathrm{Cl}^{-}$serem absorvidos mais rapidamente que os íons $\mathrm{Ca}^{2+} \mathrm{e}$ $\mathrm{SO}_{4}{ }^{2-}$ (Mengel \& Kirkby, 1987).

\section{Conclusões}

1. A absorção de cátions e de ânions pelo capimcoastcross aumenta em função das doses de $\mathrm{N}$ aplicadas tanto na forma de uréia, como de nitrato de amônio, sendo maior com o nitrato de amônio.
2. Doses altas de nitrogênio aplicadas em capimcoastcross, na forma de uréia ou de nitrato de amônio, favorecem a absorção de cátions e de ânions.

\section{Agradecimentos}

Ao convênio Embrapa-Petrobrás, pela contribuição com uma parte dos recursos financeiros; ao CNPq, pela bolsa concedida a Odo Primavesi.

\section{Referências}

BOUMAN, O.T.; CURTIN, D.; CAMPBELL, C.A.; BIEDERBECK, V.O.; UKRINETZ, H. Soil acidification from longterm use of anhydrous ammonia and urea. Soil Science Society of American Journal, v.59, p.1488-1494, 1995.

CANTARELLA, H.; CORRÊA, L.; PRIMAVESI, A.C.; FREITAS, A.R.; SILVA, A.G. Ammonia losses by volatilization from coastcross pasture fertilized with two nitrogen sources. In: INTERNATIONAL GRASSLAND CONGRESS, 19., 2001, São Pedro. Proceedings. Piracicaba: FEALQ, 2001. p.190-192.

CANTARElla, H.; CORRÊA, L.A.; PRIMAVESI, O.; PRIMAVESI, A.C. Fertilidade do solo em sistemas intensivos de manejo de pastagens. In: SIMPÓSIO SOBRE MANEJO DE PASTAGENS, 19., 2002, Piracicaba. Anais. Piracicaba: FEALQ, 2002. p.129-131.

CANTARELLA, H.; MATTOS JÚNIOR, D.; QUAGGIO, J.A.; RIGOLIN, A.T. Fruit yield of Valencia sweet orange fertilized with different $\mathrm{N}$ sources and the loss of applied N. Nutrient Cycling in Agroecosystems, v.67, p.215-223, 2003.

CORRÊA, L.A.; CANTARELlA, H.; PRIMAVESI, A.C.; PRIMAVESI, O.; FREITAS, A.R.; SILVA, A.G.; POTT, E.B. Dry matter production response of coastcross (Cynodon dactylon (L.) Pears) to sources and rates of nitrogen. In: INTERNATIONAL GRASSLAND CONGRESS, 19., 2001, São Pedro. Proceedings. Piracicaba: FEALQ, 2001. p.193-195.

COX, W.J.; REISENAUER, H.M. Growth and ion uptake by wheat supplied nitrogen as nitrate or ammonium, or both. Plant and Soil, v.38, p.363-380, 1973.

ENGELS, C.; MARSCHNER, H. Plant uptake and utilization of nitrogen. In: BACON, P.E. (Ed.). Nitrogen fertilization in the environment. New York: Marcel Dekker, 1995. p.41-81.

FÖHSE, D.; CLAASSEN, N.; JUNGK, A. Phosphorus efficiency of plants. II. Significance of root radius, root hairs and cation-anion balance for phosphorus influx in seven plant species. Plant and Soil, v.132, p.261-272, 1991.

JARVIS, S.C.; ROBSON, A.D. The effect of nitrogen nutrition of plants on the development of acidity in West Australian soils. I. Effects with subterranean clover grown under leaching conditions. Australian Journal of Agricultural Research, v.34, p.341-353, 1983.

KIRKBY, E.A.; KNIGHT, A.H. Influence of the level of nitrate nutrition on ion uptake and assimilation, organic acid accumulation, 
and cation-anion balance in whole tomato plants. Plant Physiology, v.60, p.349-353, 1977.

KIRKBY, E.A.; ARMSTRONG, M.J. Nitrate uptake by root as regulated by nitrate assimilation in the shoot of castor oil plants. Plant Physiology, v.65, p.286-290, 1980.

MALAVOLTA, E. Manual de química agrícola: adubos e adubação. 3.ed. São Paulo: Editora Agronômica Ceres, 1981. 596p.

MALAVOLTA, E.; VITTI, G.C.; OLIVEIRA, S.A. Avaliação do estado nutricional das plantas: princípios e aplicações. Piracicaba: Associação Brasileira para a Pesquisa de Potassa e Fosfato, 1989. 201p.

MARSCHNER, H. Mineral nutrition of higher plants. $2^{\text {nd }} e d$. London: Academic Press, 1995. 889p.

MATTOS JÚNIOR, D.; CANTARELLA, H.; RAIJ, B. van. Manuseio e conservação de amostras de solo para preservação de nitrogênio inorgânico. Revista Brasileira de Ciência do Solo, v.19, p.423-431, 1995.

MELLO, F.A.F. Uréia Fertilizante. Campinas: Fundação Cargill, 1987. 192p.

MENGEL, K.; KIRKBY, E.A. Principles of plant nutrition. 4.ed. Bern: International Potash Institute, 1987. 655p.
PRIMAVESI, O.; CORRÊA, L.A.; PRIMAVESI, A.C.; CANTARELLA, H.; ARMELIN, M.J.A.; SILVA, A.G.; FREITAS, A.R. Adubação com uréia em pastagem de Cynodon dactylon cv. Coastcross sob manejo rotacionado: eficiência e perdas. São Carlos: Embrapa Pecuária Sudeste, 2001. 42p. (Embrapa Pecuária Sudeste. Circular Técnica, 30).

RAIJ, B. van; DIEST, A. Utilization of phosphate from different sources by six plant species. Plant and Soil, v.51, p.577-589, 1979.

RAIJ, B. van; CANTARELLA, H.; FURLANI, P.R. Efeito, na reação do solo, da absorção de amônio e nitrato pelo sorgo, na presença e ausência de gesso. Revista Brasileira Ciência do Solo, v.12, p.131136, 1988.

RAIJ, B. van; ANDRADE, J.C.; CANTARELLA, H.; QUAGGIO, J.A. (Ed.). Análise química para avaliação da fertilidade de solos tropicais. Campinas: IAC, 2001. 285p.

TEDESCO, M.J.; VOLKWEISS, S.J.; BOHNEN, H. Análises de solo, plantas e outros materiais. Porto Alegre: Universidade Federal do Rio Grande do Sul, 1985. 188p. (Universidade Federal do Rio Grande do Sul. Boletim técnico, 5).

WHITEHEAD, D.C. Grassland nitrogen. Wallingford: CAB International, 1995. 397p.

Recebido em 14 de junho de 2004 e aprovado em 4 de outubro de 2004 